\title{
HISTÓRIA DA PROFISSÃO DOCENTE EM NATAL/RN (1908-1920)
}

\section{History of educator's profession in Natal-RN-Brazil (1908-1920)}

\author{
Maria Arisnete Câmara de Morais ${ }^{a}$, Francinaide de Lima Silva ${ }^{\mathrm{b}}$ \\ a Pesquisadora do CNPq, Professora do PPGED/UFRN, Natal, Rio Grande do \\ Norte, RN - Brasil, e-mail: arisnete@terra.com.br \\ b Mestranda do PPGED/UFRN, Bolsista da CAPES, Natal, Rio Grande do Norte, \\ RN - Brasil, e-mail: francinaide_pedagog@yahoo.com.br
}

\section{Resumo}

Este trabalho analisa a história da formação de professores em Natal, Rio Grande do Norte, entre 1908 e a década de 1920, época em que ocorreu a Reforma do Ensino (Lei n. 249/1907 e Lei n. 405/1916) que consolidou a profissão docente. Fundamenta-se em documentos localizados, principalmente, no Instituto Histórico e Geográfico do Rio Grande do Norte como Atas, Ofícios, Relatórios dos Diretores da Instrução Pública, em Leis, Decretos, Mensagens do Governo além de artigos do jornal $A$ República e da revista Pedagogium (19211925). O estudo evidencia que as políticas públicas privilegiavam a formação de docentes para a Escola Normal de Natal, espaço das práticas pedagógicas que produzem saberes e legitimam a instrução.

Palavras-chave: História da educação. Formação de professores. Escola normal.

Rev. Diálogo Educ., Curitiba, v. 9, n. 27, p. 267-278, maio/ago. 2009 


\section{Abstract}

This work analyses the history in the deals with professorial education of the Escola Normal in Natal, Rio Grande do Norte, Brazil, between 1908 and 1920 when Educational Reforms (Law n. 249, November 22 $2^{\text {nd }}$ of 1907 and Law n. 405/1916) which consolidated the Educator's profession. The research is based on documents such as meeting reports, Official minutes and Public Instruction Director's reports, Laws, Decrees, Governmental Messages and newspaper articles from A República and the Rio Grande do Norte Professorial Association-Pedagogium Periodical (1921-1925). Thus, the study evidences that public policies privilege professorial education in the Escola Normal of Natal, considered a place for pedagogical practices that produce knowledge and legitimate instruction.

Keywords: History of education. Professorial education. Primary education.

\section{As reformas do ensino no Rio Grande do Norte}

O presente artigo analisa a história da formação de professores em Natal, Rio Grande do Norte, entre 1908 e a década de 1920. Fundamenta-se em documentos localizados, principalmente, no Instituto Histórico e Geográfico do Rio Grande do Norte (IHGRN) como Atas, Ofícios, Relatórios dos Diretores da Instrução Pública, em Leis, Decretos, Mensagens do Governo, além de artigos do jornal $A$ República e da revista Pedagogium (1921-1925), edição da Associação de Professores do Rio Grande do Norte (APRN). A data inicial deste recorte justifica-se por ter sido este o momento da criação de uma instituição específica para a formação docente associada à implantação de uma rede de Grupos Escolares. Na década seguinte, sucessivos atos legislativos concernentes à educação são aprovados e estabelecem práticas peculiares ao magistério e, por conseguinte, fortalecem a profissão.

O cerne das políticas da educação eram as Reformas da Instrução que tinham a formação de professores como seu principal instrumento para o progresso do ensino. Neste período, ocorreram importantes mudanças educacionais a fim de organizar a instrução e consolidar a arte da docência. As leis e documentos revestiram o magistério de particularidades que o elevaram ao status de profissão. Códigos formativos e órgãos são instituídos pelo poder público, ao mesmo tempo em que a APRN, fundada em 04 de dezembro de 1920, congrega o professorado na defesa do ensino.

Rev. Diálogo Educ., Curitiba, v. 9, n. 27, p. 267-278, maio/ago. 2009 
Francisco Pinto de Abreu (1906), em seu Relatório anual apresentado ao Governador do Estado do Rio Grande do Norte, apontava a situação em que se encontrava o Ensino Público. Propugnador da ideia de que não haveria ensino de qualidade, nem reforma educativa, nem inovação pedagógica, sem uma adequada formação de professores ele afirmava a necessidade do preparo dos mestres, além de vencimentos compensadores. Eis a sua meta:

Rever os regulamentos para simplificar os programas e adotá-los às nossas condições de vida; reformar o sistema defeituoso de inspeção; restabelecer o fundo escolar, escriturado especialmente no tesouro, sabiamente previsto por uma lei de 1892, com a contribuição forçada de todos os municípios, incumbindo-se o estado da construção de escolas e custeio do Instituto Profissional. (RIO GRANDE DO NORTE, 1906, p. 4).

Em sua visão, a função do mestre deveria ser privilegiada através da garantia do seu bem-estar no exercício da nobre missão social de ensinar. Para ele, o professor deveria ser tão respeitado "como o vigário da freguesia" (RIO GRANDE DO NORTE, 1906, p. 5). Pinto de Abreu defendia que os poderes municipais seriam os responsáveis pelos docentes, através dos quais se alcançaria a moral, o direito e a política que honrasse o povo. O ideário republicano de formar um cidadão concedeu aos professores um papel simbólico na sociedade, envoltos numa áurea de prestígio.

Francisco Pinto de Abreu expressa o desejo de reabrir a Escola Normal de Natal e salienta a importância da inserção da mulher nessa instituição, uma vez que possuía “dotes especiais para a delicada profissão de ensinar" (RIO GRANDE DO NORTE, 1906, p. 5). Para este educador a presença feminina na Escola Normal indicava desenvolvimento, visto que em nações adiantadas como os Estados Unidos este era um fato reconhecido. As cadeiras do Ensino Primário deveriam ser "regidas exclusivamente por senhoras, atentas às suas naturais aptidões". Além disso, esta era uma ótima profissão para as moças da classe menos abastada, mais fáceis de aceitar vencimentos modestos, do que os representantes do sexo masculino.

$\mathrm{Na}$ administração do Governador Alberto Maranhão (1908-1913), ocorreram diversas mudanças no Ensino Primário. O Congresso Legislativo votou a Lei n. 249, de 22 de novembro de 1907, que autorizou o governo "a reformar a instrução pública, dando especificamente ao Ensino Primário moldes mais amplos e garantidores de sua proficuidade" (RIO GRANDE DO NORTE, 1907, p. 5). Esta Lei criava uma rede de Grupos Escolares, tendo em vista a escolarização da infância, assim como a construção da cultura letrada. Urgia a abertura de uma

Rev. Diálogo Educ., Curitiba, v. 9, n. 27, p. 267-278, maio/ago. 2009 
Escola Normal para suprir o Estado com profissionais de educação qualificados. Logo, a condição necessária ao êxito desta mudança seria formar os novos educadores de maneira racional "consoante a orientação da moderna Pedagogia" (RIO GRANDE DO NORTE, 1908, p. 46). Desse modo, o Decreto n. 178, de 29 de abril de 1908 reabriu a Escola Normal de Natal para o preparo de professores de ambos os sexos, restabeleceu a Diretoria Geral da Instrução Pública, extinta em 1900 e criou os Grupos Escolares e Escolas Mistas na capital e em outros municípios.

O Grupo Escolar Augusto Severo, criado pelo Decreto n. 174, de 5 de março de 1908, foi a primeira instituição primária instalada no bairro da Ribeira, em Natal. Desde sua fundação, servia à prática dos normalistas. Por este motivo, o Decreto n. 198, de 10 de maio de 1909, elevou este estabelecimento à categoria de Escola Modelo onde ocorreria a prática dos alunos formados pela Escola Normal de Natal. Os normalistas que se sobressaíam na sala de aula tinham preferência na ocupação das cadeiras das escolas do Grupo Modelo, na falta de professores diplomados. Os alunos-mestres seriam designados pelo Governador do Estado e prestariam serviços à instituição. Quando diplomados, tinham prioridade para o preenchimento efetivo dos referidos cargos, como também em outras instituições públicas de Ensino Primário.

A Lei n. 284, de 30 de novembro de 1909, ratifica a reforma da Instrução Pública e edita vários decretos a respeito do Código de Ensino (Decreto n. 214, de 26 de janeiro de 1910; Decreto n. 239, de 15 de dezembro de 1910; Decreto n. 359, de 22 de dezembro de 1913). A partir deste dispositivo o Curso Normal deixa de ter duração de três anos para ser ministrado em quatro anos. Este Código de Ensino efetivava as normas educativas e instituía cargos de Diretor da Escola Normal, antes exercido pelo Diretor Geral de Instrução Pública. Este regulamento admitia aos normalistas a regência das classes do Grupo Modelo, assim como estabelecia a inspeção das escolas públicas e particulares e reforçava a junção do Ensino Primário graduado e metódico com a Escola Normal.

Outras medidas surgiram com a finalidade de aprimorar a formação docente no Rio Grande do Norte. A Lei n. 382, de 18 de novembro de 1915, organiza o ensino em Primário, Normal e Profissional (RIO GRANDE DO NORTE, 1917b, p. 6). Intelectuais como Manoel Dantas, Henrique Castriciano, Antônio José de Melo e Souza, José Augusto Bezerra de Medeiros e Moisés Soares reuniram-se e apresentaram uma proposta de reforma. Desta reunião surge a Lei n. 405, de 29 de novembro de 1916, sancionada pelo então Governador Joaquim Ferreira Chaves (1914-1920).

A denominada Lei Orgânica orientou a educação norte-rio-grandense até a década de 1930. Criou os Conselhos Escolares para fiscalizar o ensino nas escolas públicas e particulares. Estes representavam o Estado no ensino local e eram responsáveis pelo recenseamento de toda a população em idade escolar. A

Rev. Diálogo Educ., Curitiba, v. 9, n. 27, p. 267-278, maio/ago. 2009 
norma que regia a instrução estabelecia também o Conselho Superior de Instrução Pública que, por sua vez, tinha por finalidade estudar e aplicar as leis do ensino, com o intuito de auxiliar a Diretoria Geral. A norma delineava e ampliava os papéis dos diplomados pela Escola Normal. Além de professores nas escolas primárias, os profissionais ocupavam cargos técnicos de diretores, inspetores, fiscais e conselheiros de ensino, engajados com a causa educacional. Surge a revista Pedagogium (1921-1925), principal veículo de divulgação dos educadores da época.

Entre as normas educativas, um destaque para a criação do Departamento de Educação (Decreto n. 265, de 24 de março de 1925) e o Conselho de Educação (Ato de 10 de março de 1925). Órgãos criados para fiscalizar mais a escola e o professor, através da criação de regimentos e medidas que regulavam a conduta moral e a prática docente. O Conselho de Educação era composto por comissões pedagógicas, legislativas e judiciárias. Elas visavam auxiliar na proposta de livros a serem adotados no ensino, na confecção de regimentos, editais de concursos, dentre outros casos de caráter jurídico.

\section{Uma escola de formação em Natal}

Em meados do século XIX foram criadas as primeiras Escolas Normais do país para a formação de docentes. Azevedo (1976, p. 94) registra a criação das Escolas Normais no Brasil: a de Niterói, em 1835; a da Bahia, em 1836; a do Ceará, em 1845; a de São Paulo, em 1846 e a do Rio de Janeiro, em 1880.

Em Natal, a Escola Normal teve sua primeira fundação autorizada pela Lei n. 671, de 05 de agosto de 1873. Estava entre as primeiras instituições criadas no Brasil e formou três docentes: Celso Caldas, Joaquim Peregrino e Antônio Gomes Leite. Funcionou durante quatro anos quando foi extinta pela Lei n. 809, de 19 de novembro de 1877.

A segunda Escola Normal, criada já na República, "foi nati-morta", na expressão de Nestor Lima. Apenas se sabe que foi criada pelo Governador Adolfo Gordo, por decreto de 8 de fevereiro de 1890. A terceira Escola Normal, que é a de Pedro Velho e data de 1882, só chegou a ser instalada em 1896. Era exclusivamente masculina. Diplomou, até 1901, cinco professores: Pedro Alexandrino, Pedro Gurgel de Oliveira, Lourenço Gurgel do Amaral, Alfredo Celso Fernandes e Luiz Marinho Simas. "Extinguiu-se à falta de alunos, ou melhor, morreu de inanição”. É a análise de Nestor dos Santos Lima (MORAIS, 2006, p. 74).

Finalmente, foi a Escola Normal de Natal criada em 13 de maio de 1908 que cumpriu o objetivo de preparar os professores e aperfeiçoar a Escola Primária do Estado, instalada nas dependências do Ateneu Rio-Grandense com suas cadeiras providas mediante contrato e a sua direção confiada a um dos lentes

Rev. Diálogo Educ., Curitiba, v. 9, n. 27, p. 267-278, maio/ago. 2009 
do Ateneu. A primeira turma formada pela Escola Normal de Natal, em 04 de dezembro de 1910, diplomou sete professores e vinte professoras. Na ocasião formaram-se:

Luiz Antônio dos Santos Lima, Severino Bezerra de Melo, Manuel Tavares Guerreiro, Anfilóquio Carlos Soares Câmara, Francisco Ivo Cavalcanti, José Rodrigues Filho, Luiz Garcia Soares de Araújo, Ecila Pegado Cortez, Judite de Castro Barbosa, Áurea Fernandes Barros, Olda Marinho, Stela Vésper Ferreira Gonçalves, Beatriz Cortez, Arcelina Fernandes, Guiomar de França, Anita de Oliveira, Francisca Soares da Câmara, Maria Natália da Fonseca, Maria Abigail Mendonça, Maria das Graças Pio, Clara Fagundes, Maria da Conceição Fagundes, Maria Julieta de Oliveira, Maria Belém Câmara, Maria do Carmo Navarro, Helena Botelho, Josefa Botelho. (MORAIS, 2006, p. 75).

Começava a tendência para a feminização do magistério, notada em outras regiões do país como São Paulo, Rio de Janeiro e Porto Alegre (SOARES, 1998, p. 56). Os homens abandonavam as salas de aula. A feminização do magistério ganhava espaço. Era a possibilidade que a mulher dispunha de se engajar no mundo do trabalho. Tal possibilidade não subverteria as funções femininas: ser mãe, esposa e dona-de-casa. Eram funções cumulativas.

Após a diplomação, os professores estavam habilitados a lecionar nos cursos primários público e privado. Para ser credenciado como professor público provisório o docente passava por exames nos quais constavam os principais pontos da prática nestes estabelecimentos primários. Fazia parte da avaliação uma prova escrita com a descrição de um passeio escolar, a apreciação de uma Festa da Árvore e de uma festa nacional realizada na escola, cujo tema seria a influência da educação na formação do caráter nacional.

A Escola Normal de Natal funcionou no Ateneu Norte-RioGrandense até 31 de dezembro de 1910. No ano seguinte, mudou-se para as instalações do "edifício escolar de mais amplas e majestosas proporções", o Grupo Escolar Augusto Severo, na Praça homônima. "Todo mundo sabia que era ali a Escola Normal, mas se dizia que era o Grupo Modelo" (MORAIS, 2006, p. 76).

Nesse estabelecimento funcionavam os três elementos que compunham uma Escola Normal de segundo ciclo, que era a formação de professores primários em três anos; ou seja, um Grupo Escolar e um Jardim Modelo, que serviam à prática das normalistas. A partir de 1910 o Ensino Normal passou a ser ministrado em quatro anos e compunha-se das seguintes disciplinas:

Rev. Diálogo Educ., Curitiba, v. 9, n. 27, p. 267-278, maio/ago. 2009 
Português, Francês, Aritmética, Noções de Geometria teórica e prática, Geografia Geral e particular do Brasil, História Geral e particular do Brasil, Educação Moral e Cívica, Noções de Física e Química aplicadas à vida prática, História Natural aplicada à agricultura e à criação dos animais. Este corpo de conhecimentos gerais e científicos era ministrado nos dois primeiros anos. Eram disciplinas especializadas que dotavam o Curso Normal de um caráter propedêutico à profissão docente. As disciplinas que compunham os dois últimos anos consistiam em: Pedagogia, História da Educação, Economia e Leis Escolares, Higiene Escolar, Desenho, Princípios de Música e Cantos Escolares, Trabalhos Manuais, Economia e Artes Domésticas (para o sexo feminino), Educação Física e Exercícios Infantis. Por fim, o local da prática seria no Grupo Escolar Modelo Augusto Severo. Esta experiência prática no cotidiano de uma instituição primária introduzia os docentes no magistério e dava ao Curso Normal aspectos instrumentais.

No final dos dois primeiros anos, os alunos submetiam-se a uma avaliação para aferir o aprimoramento nas matérias. Ao término dos dois últimos passavam por mais um exame de suas aptidões nas matérias e, por fim, na prática escolar adquirida no Grupo Modelo durante o ano letivo. Concluído o Curso Normal, os docentes estavam habilitados para atuarem no Ensino Primário, como professores em qualquer uma das instituições primárias do Rio Grande do Norte:

O Estado só reconhece, como tais, para o aproveitamento efetivo no magistério público, os professores diplomados pela Escola Normal do Rio Grande do Norte, externato dirigido por pessoa de livre nomeação do Governador, dentre os professores ou dentre os profissionais estranhos ao mesmo estabelecimento. (RIO GRANDE DO NORTE. A Reforma do Ensino, 1917b, p. 11).

Quando diplomados, os professores tinham o incentivo do Estado através do Livro de Honra. Os que obtivessem boas notas recebiam elogios, votos de louvor e outros tipos de comendas. O Livro de Honra foi criado pelo Artigo 195, da Lei Orgânica do Ensino de 1916, no qual os professores primários que se destacassem eram homenageados. Um estímulo à prática docente. $\mathrm{O}$ assentamento era considerado uma recompensa aos educadores que mais trabalhassem pela difusão e desenvolvimento do ensino. Para receber a láurea, os mestres tinham que se distinguir pelo trabalho intelectual, pela técnica escolar, bem como no cumprimento dos deveres profissionais e na dedicação à causa da instrução.

Em 26 de março de 1919 eram louvados pelo Diretor Geral da Instrução Pública, Manoel Dantas, e publicados no Livro de Honra os nomes dos professores primários que se destacaram no cenário educativo, bem como os respectivos números de alunos que obtiveram êxito escolar (RIO GRANDE DO

Rev. Diálogo Educ., Curitiba, v. 9, n. 27, p. 267-278, maio/ago. 2009 
NORTE. Livro de Atos, 1919, p. 44). Constava neste livro os nomes dos professores primários Manoel Tavares Guerreiro, Luiz Antônio dos Santos Lima, Stella Ferreira Gonçalves, Oscar Wanderley, Guiomar de França, Stellita Melo e Anna Silva de Araújo. Professores estes que se destacaram, ao longo da vida, enquanto intelectuais atuantes na sociedade.

No entanto, esta não era a única manifestação honrosa concedida aos mestres. O Registro Profissional facultava aos docentes competentes e de boa conduta, informações apropriadas em concursos de títulos. O regulamento conferia o Prêmio Pestalozzi, uma medalha de ouro com efígie deste educador ou, ainda, o Prêmio Fröebel, uma medalha de prata com efígie do pedagogo (RIO GRANDE DO NORTE, Código de Ensino, 1910, p. 125). Além da comenda, os docentes ganhavam viagens para observar e relatar os progressos do ensino em outros Estados.

O combate ao analfabetismo, os meios práticos que podiam ser empregados com este fim, deveriam ser de atenção dos habilitandos. Os professores eram submetidos aos exames orais nas disciplinas ministradas nas escolas primárias. A prova em Língua Francesa era obrigatória. No que diz respeito à Pedagogia, os candidatos teriam que versar sobre os aspectos sumários da educação física, intelectual, religiosa e cívica. Os métodos de ensino, recompensas e punições também deveriam ser enfocados. Os candidatos aprovados fariam a prova prática para a avaliação de sua aptidão pedagógica.

A ação pedagógica dos professores primários era norteada por concepções didático-metodológicas, apresentadas nos Regimentos Internos dos Grupos Escolares, que normatizava também as Escolas Isoladas. Este documento incentivava a imposição da disciplina em sala de aula, regulava o comportamento de alunos e professores no interior da instituição escolar, assim como a disseminação de valores e normas educacionais e sociais. A mudança proposta nestes Regimentos Internos se materializava no ambiente escolar.

O mês de maio era singular. Neste mês realizava-se a Festa da Natureza, bem como a festa do patrono do Grupo Escolar Augusto Severo. No dia 12 de maio os alunos rendiam homenagens a Augusto Severo de Albuquerque Maranhão, rememorando o aniversário de morte deste norte-rio-grandense que dedicou-se ao estudo sobre a navegação aérea. Ele morreu a 12 de maio de 1902, na França, ao realizar um experimento com o balão dirigível denominado Pax.

As árvores, as flores, os frutos, as aves tinham "um culto fervoroso, de onde o coração humano aprende logo a virtude de praticar o bem" (BARBOSA, 1914, p. 1). As festas do Grupo Escolar Augusto Severo cultuavam a Pátria com cânticos, exercícios, poesias. Os alunos decoravam e declamavam poesias, faziam discursos. Na Festa das Aves, uma metáfora da liberdade da ave com a Independência do Brasil, o objetivo era desenvolver os sentidos e o físico das crianças.

Rev. Diálogo Educ., Curitiba, v. 9, n. 27, p. 267-278, maio/ago. 2009 
Tudo quanto se aprende agora é proveitoso, nutre o espírito desabrochante, sem aquela cantilena monótona das tabuadas e das demais disciplinas que o método antigo sabia estabelecer. A escola ensina ser tudo: útil, grande e bom. Explica os exemplos de modo a alma ficar bem iluminada e os meninos desejam aprender convictos de que todas as lições têm um substancioso interesse e um extraordinário fim (BARBOSA, 1914, p. 1).

Os processos de ensino intuitivo, o aprender-fazendo, e a formação específica do educador tinham relação intrínseca com a Pedagogia Nova. A prática dos preceitos modernos no ato de educar conferia unidade teórica, técnica e profissional, que buscavam garantir o efetivo proveito da instrução primária e valorizavam a profissão do professor primário.

O Curso de Férias, realizado em janeiro dos anos de 1925 e 1926, promovido pelo Departamento de Educação, reunia os educadores, em seu primeiro ano, no Salão da Escola Normal de Natal e no seguinte no Teatro Carlos Gomes. Nestas reuniões os docentes ouviam palestras sobre doenças infectocontagiosas, o ensino da língua, aritmética, geometria, cartografia, escrituração e administração escolar e orientações gerais sobre o ensino.

As assembleias tinham uma média de frequência de cento e vinte docentes da rede pública de ensino. Conforme Nestor Lima (1927) a Escola Normal de Natal havia formado mais de duzentos professores primários e a de Mossoró criada pelo Decreto n. 165, de 19 de janeiro de 1922, trinta, em fins da década de 1920. Muitos docentes formados na Escola Normal atuavam em instituições públicas como os Grupos Escolares "considerados escolas de qualidade e de grande prestígio social que se estendia ao corpo docente" (SOUZA, 1998, p. 73).

A atividade de ensinar era um ofício. Produzia práticas, consolidava a profissão docente e delineava condutas e mentalidades. Nas salas de aula, nos corredores, nos pátios e em outros meios, os professores representavam os artífices da moral atendiam aos preceitos vigentes. Enfrentavam desafios, ocupavam novos postos de trabalho na inspeção, fiscalização e produção de leis relativas ao ensino. Formas do fazer docente que evidenciam a história da profissão docente no Rio Grande do Norte.

\section{CONSIDERAÇÕES FINAIS}

As Reformas de Ensino do Estado desenvolveram as configurações do Ensino Primário e Normal ao normatizarem as instituições formadoras de

Rev. Diálogo Educ., Curitiba, v. 9, n. 27, p. 267-278, maio/ago. 2009 
educadores e a carreira profissional. Indicavam os modos de fazer e condutas específicas na Escola Primária. As Escolas Normais são espaço de afirmação profissional, um lugar de reflexão sobre as práticas, que conferem aos professores a representação dos profissionais que produzem saberes e legitimam a profissão docente. Estas instituições de formação docente dão autenticidade a um saber produzido no exterior da profissão, que veicula uma concepção dos professores centrada na difusão e na transmissão de conhecimentos.

As singularidades locais e institucionais demonstram que a consolidação do ensino profissional para o magistério acontece no mesmo momento em que são delineadas as diretrizes para a organização educacional.

O estudo evidencia que as políticas públicas privilegiavam a formação de docente para a Escola Normal de Natal, espaço das práticas pedagógicas que produzem saberes e legitimam a instrução.

\section{REFERÊNCIAS}

ALMEIDA, Jane Soares de. Mulher e educação: a paixão pelo possível. São Paulo: Fundação Editora da UNESP, 1998.

BOLETIM PEDAGÓGICO. Diário do Natal, Natal, p. 1, 11 set. 1909.

AZEVEDO, Fernando. A transmissão da cultura. In: A cultura brasileira. 5. ed. São Paulo: Melhoramentos; Brasília: INL, 1976.

BARBOSA, Ponciano. Quadro triste. A República, Natal, p. 1, 13 ago. 1914. CASCUDO, Câmara. História da cidade do Natal. 3. ed. Natal: RN Econômico; Instituto Histórico e Geográfico do Rio Grande do Norte, 1999.

LIMA, Nestor dos Santos. Um século de ensino primário. Natal: Tipografia de A República, 1927.

MORAIS, Maria Arisnete Câmara de. Chicuta Nolasco Fernandes, intelectual de mérito. Natal: Editorial A República, 2006. (Série Educação e Educadores do Rio Grande do Norte, v. 2).

NÓVOA, Antônio. Formação de professores e profissão docente. In: NÓVOA, Antônio (Coord.). Os professores e a sua formação. 2. ed. Tradução por Graça Cunha, Cândida Hespanha, Conceição Afonso e José António Sousa Tavares. Lisboa: Publicações Dom Quixote, Instituto de Inovação Educacional, 1997.

Rev. Diálogo Educ., Curitiba, v. 9, n. 27, p. 267-278, maio/ago. 2009 
PEDAGOGIUM. Revista da Associação de Professores do Rio Grande do Norte. Natal: Tipografia de A República, 1921-1925.

RIO GRANDE DO NORTE. Relatório anual da instrução pública. Natal: Tipografia de A República, 1906.

RIO GRANDE DO NORTE. Atos legislativos e decretos do Governo do Estado do Rio Grande do Norte. Decreto n. 239, de 15 de dezembro de 1910. Código de Ensino. Natal: Tipografia de A República, 1910. p.119-148.

RIO GRANDE DO NORTE. Lei n. 405, de 29 de novembro de 1916. Reorganiza o Ensino Primário, Secundário e Profissional. Natal: Tipografia de A República, 1917a.

RIO GRANDE DO NORTE. A reforma do ensino. Ligeiro comentário à Lei n. 405, de 29 de novembro de 1916. Reorganiza o Ensino Primário, Secundário e Profissional. Natal: Tipografia de A República, 1917b.

RIO GRANDE DO NORTE (1917c). Diretoria Geral de Instrução Pública. Registro de ofícios, n. 57, 1917. Natal. (Manuscrito).

RIO GRANDE DO NORTE. Atos legislativos e decretos do Governo do Estado do Rio Grande do Norte (1907-1913). n. 10. Natal: Tipografia de A República, 1907-1913.

RIO GRANDE DO NORTE. Departamento da Instrução Pública. Livro de atos da Diretoria Geral da Instrução Pública (1914-1919). Registro de atas e resoluções. Livro n. 2. Natal. (Manuscrito). 50f.

RIO GRANDE DO NORTE. Departamento da Instrução Pública. Registro de ofícios (1918-1920). Livro n. 5 (completo). Natal. (Manuscrito). $200 f$.

RIO GRANDE DO NORTE. Departamento da Instrução Pública. Registro das atas e resoluções (1919-1923). Livro n. 3. Natal. (Manuscrito). 50f.

RIO GRANDE DO NORTE. Livro de assinaturas de presença e atas do Curso de Férias (1925-1926). Natal, Manuscrito. 1926. 50f.

RIO GRANDE DO NORTE. Regulamento Geral do Departamento de Educação e Regimento Interno do Conselho de Educação. Decreto n. 265, de 24 de março de 1925. Manda observar e cumprir o regulamento do Departamento de Educação do Estado. Ato de 10 de março de 1925. Aprova e manda publicar o Regimento Interno do Conselho de Educação. Natal: Tipografia da República, 1925.

Rev. Diálogo Educ., Curitiba, v. 9, n. 27, p. 267-278, maio/ago. 2009 
SILVA, Francinaide de Lima. O Grupo Escolar Modelo Augusto Severo e a prática pedagógica de suas professoras (Natal/RN, 1908-1920). 2007. $63 \mathrm{f}$. Monografia (Curso de Pedagogia) - Universidade Federal do Rio Grande do Norte, Natal, 2007.

SOUZA, Rosa Fátima de. Templos de civilizaçãa: a implantação da Escola Primária Graduada no Estado de São Paulo (1890-1910). São Paulo: Fundação Editora da UNESP, 1998.

Recebido: 10/02/2009

Received: 02/10/2009

Aprovado: 15/03/2009

Approved: 03/15/2009

Revisado: 22/07/2009

Reviewed: 07/22/2009

Rev. Diálogo Educ., Curitiba, v. 9, n. 27, p. 267-278, maio/ago. 2009 